\title{
ANALYSIS OF CURRENT PATTERNS IN COASTAL AREAS USING X-BAND RADAR IMAGES
}

\author{
Cilia Swinkels ${ }^{1}$, Herman Peters ${ }^{2}$ and Jos van Heesen ${ }^{3}$
}

\begin{abstract}
The Seadarq software from Nortek is designed to derive wave, water depth and current information from ordinary navigation radar images. This is done by analysis of the wave propagation patterns using an inverse dispersion fitting technique. The remotely sensed data provides the unique opportunity to assess temporal and spatial propagation patterns of waves and currents over a significant stretch of water overlooked by a radar station. This exploratory study shows that radar data can provide very valuable insight in otherwise seldom disclosed current patterns. The spatial and temporal information of the radar data may allow us to calibrate our numerical model not only for water levels but now also for details in the currents patterns. Moreover, the radar data has improved the understanding of the hydrodynamics in a complex tidal inlet and around a mega-nourishment.
\end{abstract}

Keywords: remote sensing; $x$-band radar; nearshore hydrodynamics

\section{INTRODUCTION}

Coastal engineers are often confronted with a lack of field data preventing them to fully understand the physical environment that they are working in. By default, water level and wave data can easily be obtained but is often limited to a few and sometimes remote observation stations. Current measurements, if available at all, seldom consist of a longer-term data set with significant spatial coverage; often the availability of current information relies on the temporary deployment of fixed ADCP instruments or vessel surveys. Typically, numerical models are used to fill in the information gap; but whereas models can usually be calibrated accurately for the global water level distribution, the calibration of current velocities is a local matter and therefore does not guarantee reliable horizontal current distribution in the model.

The Seadarq software from Nortek may now overcome the lack of information on spatial current patterns. The software is designed to derive wave, water depth and current information from ordinary navigation radar images. This is done by analysis of the wave propagation patterns using an inverse dispersion fitting technique. The remotely sensed data provides the unique opportunity to assess temporal and spatial propagation patterns of waves and currents over a significant stretch of water overlooked by a radar station. The data coverage stands in large contrast to the scarcely available information in space and time obtained from conventional in-situ measurements. So far, we have limited experience with the use of this relatively novel data in coastal engineering projects. At a number of coastal field sites in the Netherlands, the existing navigation radar has recently been equipped with Seadarq software. In this study, the data of two of these sites is analyzed to explore the value of the current data derived from radar images.

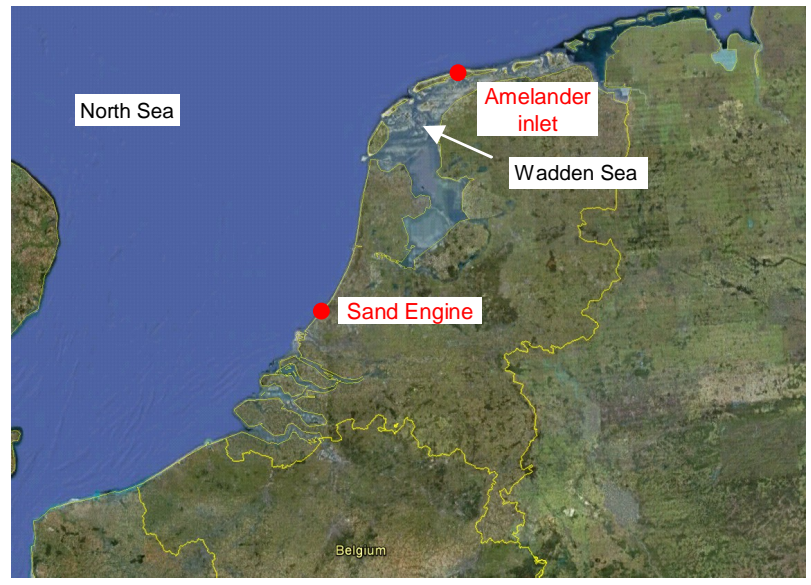

Figure 1. Field sites in the Netherlands where Seadarq data is collected

\footnotetext{
${ }^{1}$ Harbours, Coastal and Offshore Engineering, Deltares, Rotterdamseweg 185, 2529 HD, Delft, The Netherlands

${ }_{2}^{2}$ National Water Measuring Network, Rijkswaterstaat, Derde Werelddreef 1, 2622 HA, Delft, The Netherlands

${ }^{3}$ Nortek, Schipholweg 333a, 1171PL, Badhoevedorp, The Netherlands
} 
The first site is the Ameland Inlet, one of the tidal inlets between the barrier islands that separate the North Sea from the Dutch part of the Wadden Sea (see Figure 1). The Wadden Sea is a shallow tidal basin with a bathymetry characterized by tidal flats and an extensive creek and channel system. The semi-diurnal tide has a mean range of approximately $2 \mathrm{~m}$, which generates strong tidal currents through the inlet channels of up to $1.5 \mathrm{~m} / \mathrm{s}$ under normal tidal conditions. The Ameland Inlet has been extensively monitored within the framework of the $S B W$ (Strength and Loads of Water Defenses) research program commissioned by the Dutch Ministry of Infrastructure and the Environment. As part of the monitoring program, Seadarq software has been applied to the raw navigation radar data at the Ameland lighthouse since the beginning of 2010. The lighthouse overlooks the Ameland tidal inlet and the spatial coverage of the radar is approximately $70 \mathrm{~km}^{2}$ (see Figure 2).

The second field site is the Sand Engine, a mega-nourishment of sand of approximately $20 \mathrm{Mm}^{3}$ on the southwestern Dutch coast, which was constructed in 2011. The unprecedented scale of this nourishment led to questions on the response of the coastal system to the intervention and on the accuracy of the numerical model predictions that were made prior to construction. Also the impact of the unusual currents on swimmer safety was an important issue. To gain insight in the development and impact of the Sand Engine, an extensive monitoring campaign was launched. A radar station was installed $3 \mathrm{~km}$ North of the nourishment area as part of the monitoring campaign and has been in operation since June 2012 (see Figure 3).

The objectives of the current study are to make a comparison between the radar current data and dedicated numerical model computations for the above two field sites in order to:

1. analyze the current patterns in the two coastal systems;

2. if possible, improve the numerical model predictions based on the insight gained from the radar data;

3. more generally, assess the usability of the radar data for coastal engineering applications.
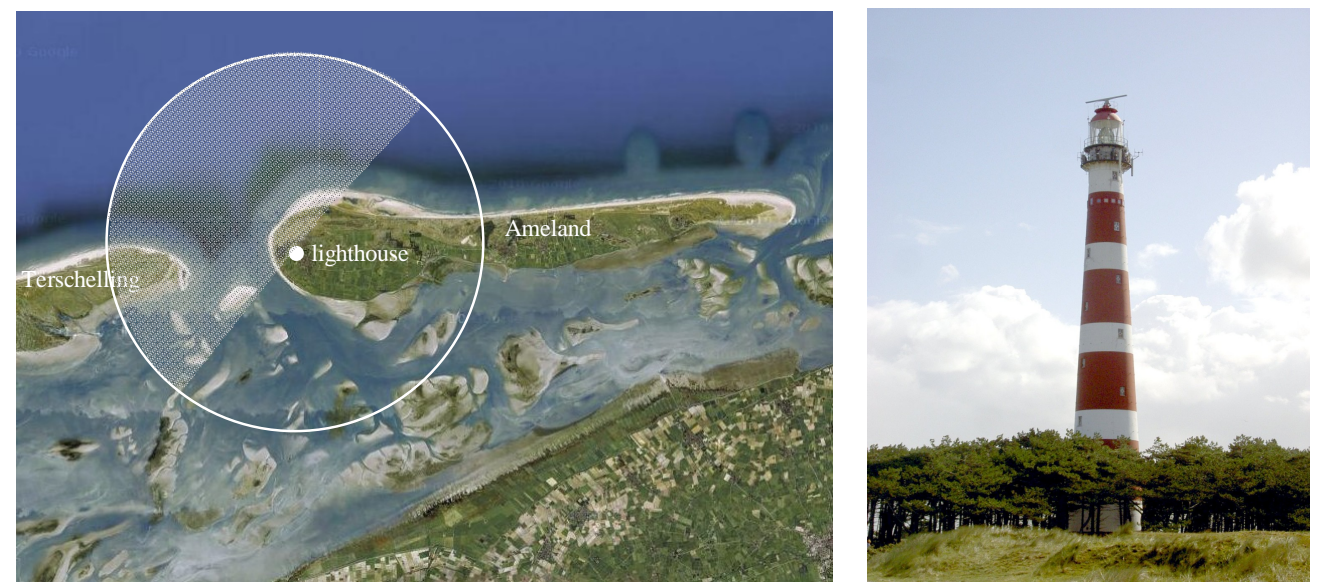

Figure 2. Left: location and approximate range of the radar of Ameland. Right: lighthouse with navigation radar mounted on top. Pictures courtesy of Google Earth and Wikipedia.

\section{BACKGROUND ON SEADARQ RADAR IMAGE ANALYSIS}

The method to derive hydrodynamic data from marine X-band radar is described by Alkyon (2006) and Gautier et al (2012a) and is based on the backscattering of the radar waves by capillary waves and short gravity waves at the sea surface. For the presence of these short waves to produce a usable radar image, wind speeds between 2 to $20 \mathrm{~m} / \mathrm{s}$ are required. The sea echo, known as sea clutter, is unwanted noise for navigational purposes but is the main input for Seadarq: amplitude modulation of the sea clutter by large gravity waves makes the wave crest patterns visible and allows for the analysis of wavelengths, wave propagation speed and direction, see for example Figure 4. 

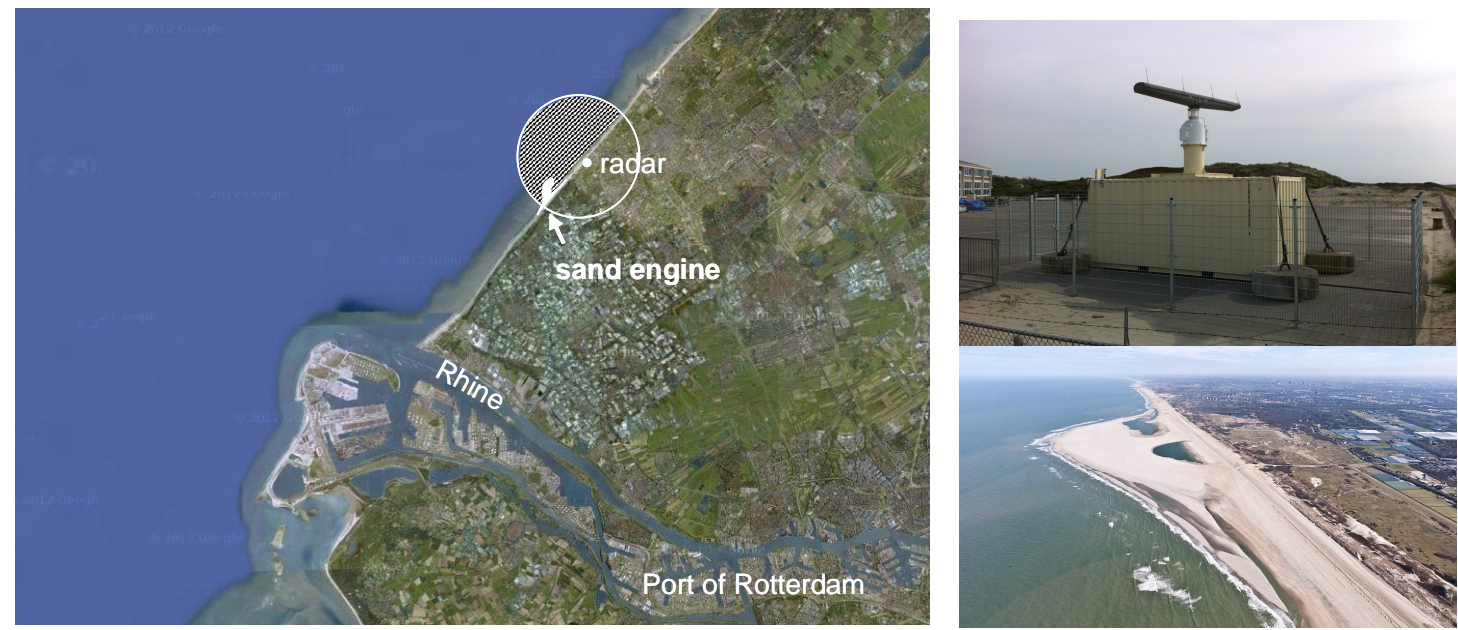

Figure 3. Left: location and approximate range of the radar at the Sand Engine. Right: radar installation and aerial photograph of the Sand Engine. Pictures courtesy of Google Earth and Wikipedia.

From a series of radar images, the wave propagation direction and the associated phase velocity can be estimated unambiguously (Gautier et al, 2012a). Hereto, the radar images need to be transformed from $(\mathrm{x}, \mathrm{y}, \mathrm{t})$ space via $3 \mathrm{~d}$ FFT to $\left(\mathrm{k}_{\mathrm{x}}, \mathrm{k}_{\mathrm{y}}, \omega\right)$ space (with $\mathrm{k}_{\mathrm{x}}, \mathrm{k}_{\mathrm{y}}$ the orthogonal components of the wave number vector and $\omega$ the angular frequency). In the absence of currents or bottom effects, the linear dispersion relation yields the undisturbed phase velocity. However, in practice the measured phase velocity estimated from the sequence of radar images will often deviate from the undisturbed phase velocity. The measured difference makes it possible to compute the current velocity as well as the average water depth with an iterative method. To estimate the velocity vector, mainly the high frequency components of the wave spectrum are used. The measured current parameter therefore represents the depth-averaged value over the vertical current profile in the upper few meters of the water column.

Typically, a sequence of 32 radar images, equivalent to about 1.6 minutes of radar measurements, over cells of approximately $1000 \times 1000 \mathrm{~m}$ are considered in the FFT analysis. The Seadarq method is based on the assumption of homogeneity of waves, currents and water depth in the analyzed resolution cells. Also, the inverse dispersion fitting technique works best for wind sea conditions with large directional and frequency spread, in which case the uncertainty in the derived parameters is lowest. The hydrodynamic parameters derived from the radar images (wave length, wave direction, wave period, water depth, current speed and direction) are provided on an output grid with resolution of 300 $\mathrm{x} 300 \mathrm{~m}$. In this study, we focus on the radar-derived currents; for an analysis of the radar-derived wave parameters see e.g. Gautier and Groeneweg (2012b).
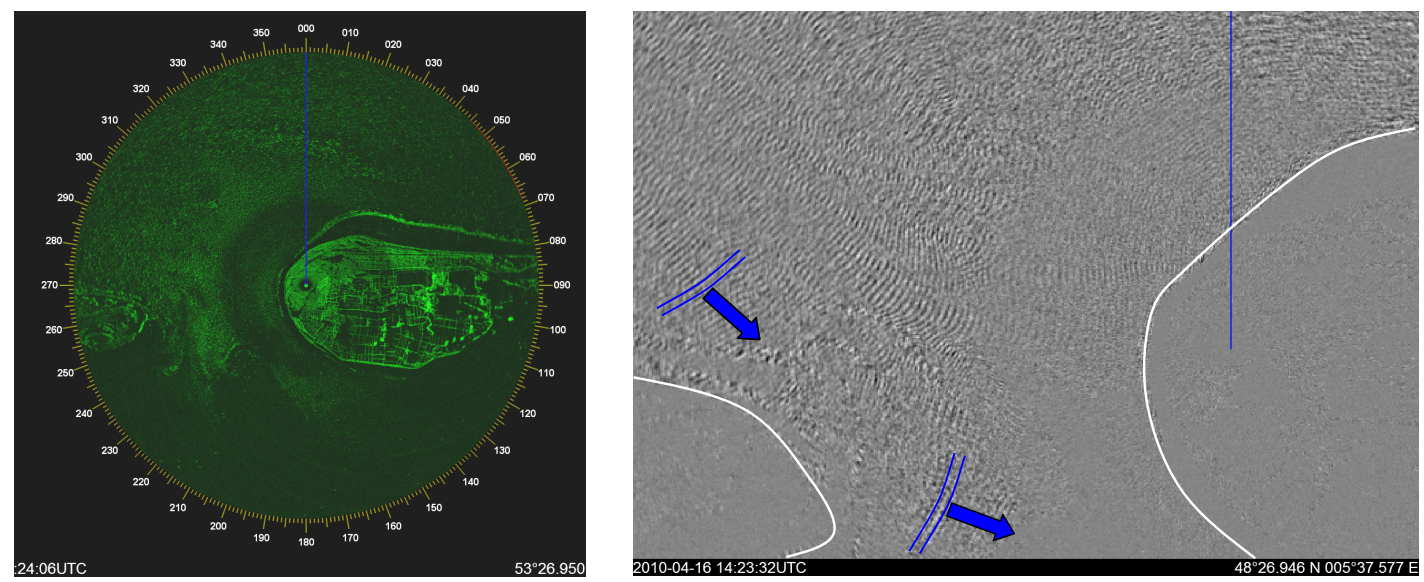

Figure 4. Left: unprocessed radar image from the Ameland Inlet. Right: close up of the inlet channel showing the wave propagation patterns in the area 


\section{Radar derived velocity fields}

In Figure 5, a typical example of a Seadarq current field is shown for the Ameland Inlet. Data is only available over the outer ebb-tidal delta; due to the depth cut off $(<3 \mathrm{~m})$ in the software, below which wave propagation deviates too much from linear wave theory, no data is available inside the shallow Wadden Sea. A number of outliers and data gaps are evident in the Seadarq data, typically in the following areas:

1. areas with strong horizontal gradients in bottom topography and currents, where due to violation of the homogeneity assumption no convergence of the algorithm is possible.

2. shallow areas where breaking waves and white water bores cause distortion of the radar reflections. This limits the capability of Seadarq to measure properties of the wave spectrum and ambient currents accurately.

3. areas at larger distance from the radar. The resolution of the radar images becomes worse on the outer edges of the radar's range thus lowering the resolving capability of Seadarq.

Using a temporal filtering technique, most outliers can easily be removed from the data set (see Deltares, 2010).

In some locations, the current direction and / or magnitude differs persistently from surrounding grid points. This can be explained by the fact that the current vectors are being determined by an algorithm that averages over different wave length groups. Ultimately, the set of wavelengths for which the standard error is lowest, is selected for determination of the current vector; this may differ from grid point to grid point. Because the different wavelength groups have a different penetration depth, the derived current vector may thus be representative for a different depth than at surrounding grid points. At present, the depth over which the current vector is valid, is not yet provided as output from the Seadarq analysis and is thus unknown.

According to Nortek, the accuracy of the current measurements is $\pm 0.1 \mathrm{~m} / \mathrm{s}$. However, no validation against in-situ observations has been carried out up to present and the accuracy of the radar current data is therefore also unknown.

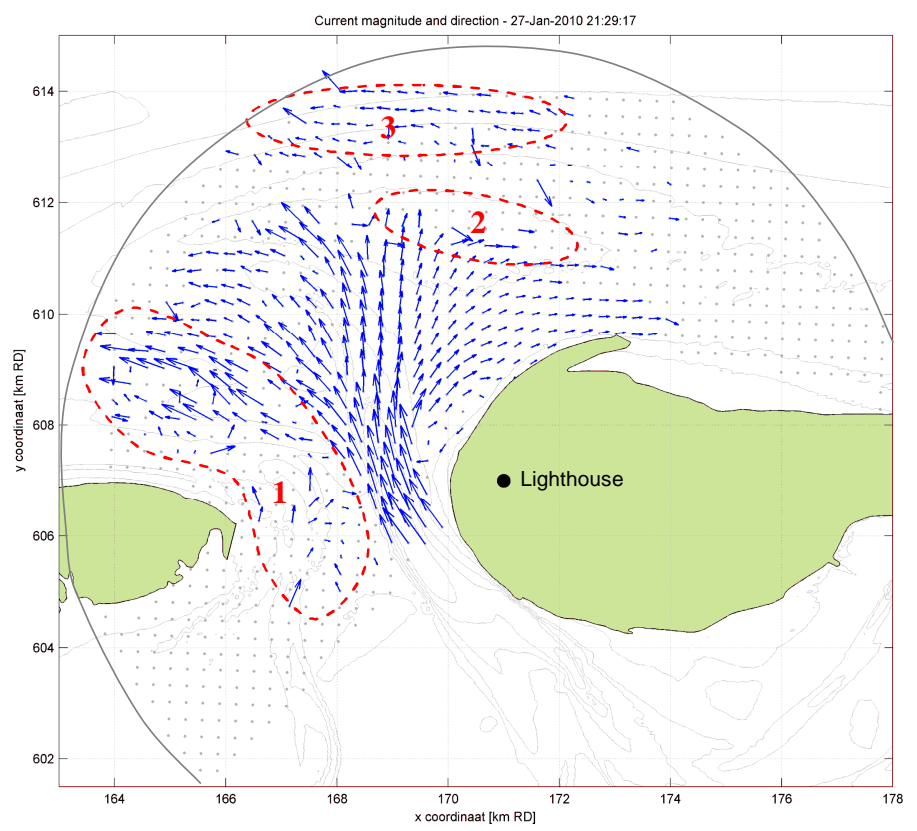

Figure 5. Example of Seadarq current field with indication of areas with high occurrence of outliers.

\section{HINDCAST OF STORM EVENTS}

To make a model versus data comparison for both field sites, numerical computations are carried out for a period with energetic wind and wave conditions. The selected storm events are hindcasted using the open source package Delft3D (oss.deltares.nl) in a coupled flow-wave simulation. Three depth-averaged hydrodynamic models are used in a nested modeling approach to cover different 
spatial scales. At the first step, the Dutch Continental Shelf Model (DCSM) is run to compute the water levels in the entire North Sea basin. The DCSM is a regional tide and surge model covering the area from the Northwest continental shelf towards the Dutch coast (see e.g. Gerritsen, 1995). The model is forced by astronomical tidal constituents at the offshore boundaries and the meteorological forcing is based on HIRLAM (the High Resolution Limited Area Model from KNMI) wind and pressure fields.

At the second step, a more detailed regional model is run to provide boundary conditions to the highest resolution nearshore model. In the Ameland Inlet case, the existing Wadden Sea model (see e.g. Deltares, 2009) and the Ameland Inlet model are run in an online nesting approach. For the Sand Engine case, the existing Kustfijn model (see e.g. Kuijper, 1993) and the local high-resolution Sand Engine model are run in an offline nesting approach. Wave effects are incorporated in the nearshore hydrodynamic model to take into account the impact of waves on the local currents. In Figure 6, an overview of the modeling domains and nesting steps is given and in Figure 7, the model bathymetry of the two high-resolution domains is shown.

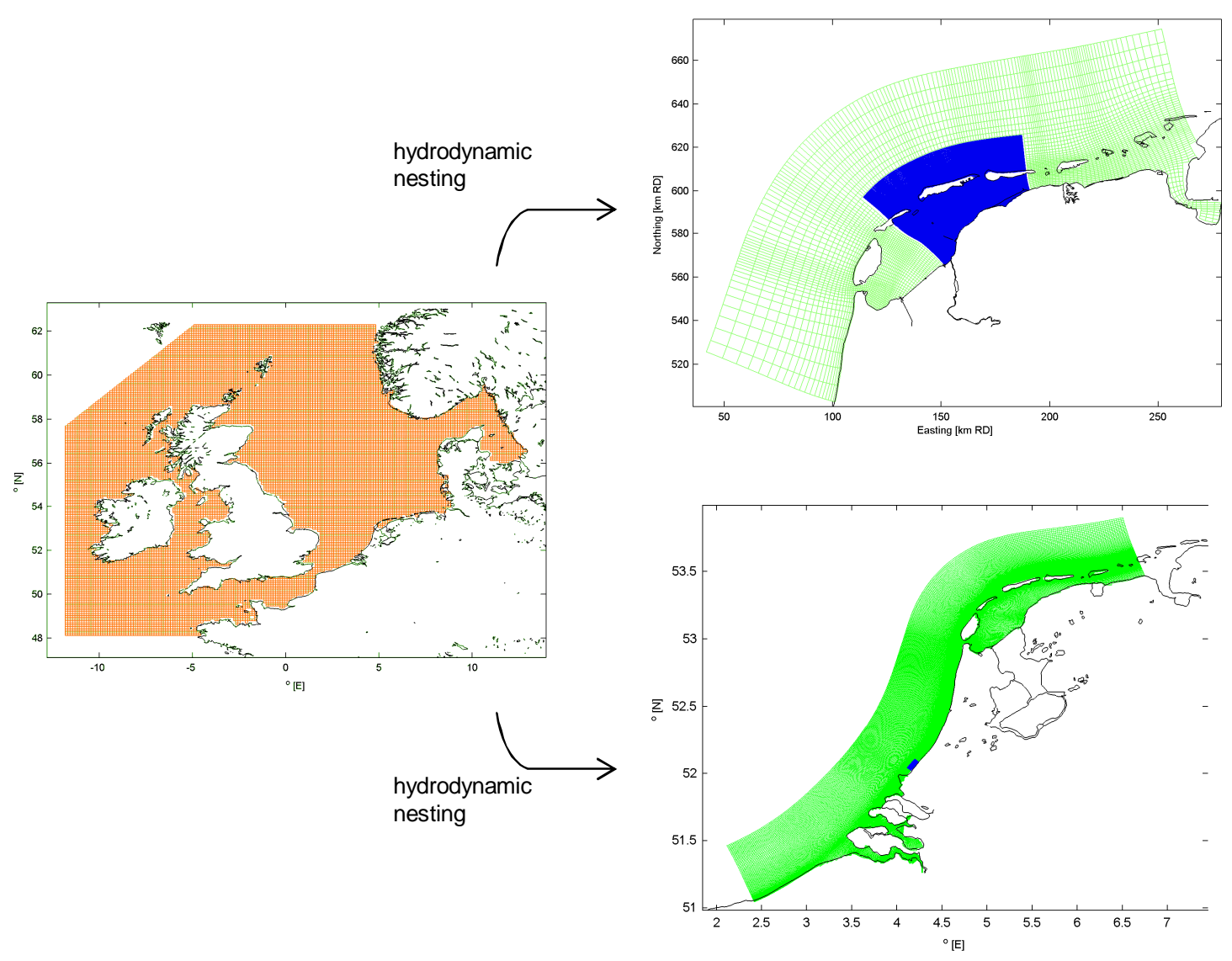

Figure 6. Computational model grids. Left: DCSM model. Right: Wadden Sea model (top) and Kustfijn model (bottom). The blue grids show the local, high-detail computational grids of the Ameland Inlet (top) and Sand Engine (bottom). 

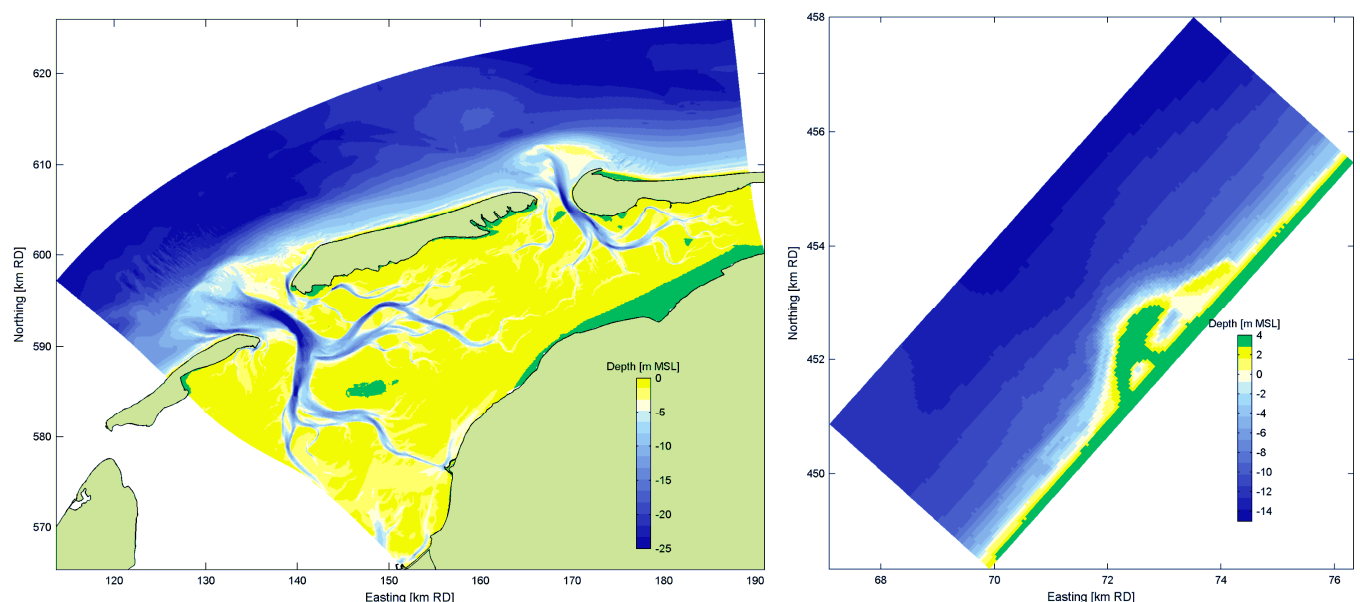

Figure 7. Model bathymetries of the Ameland Inlet model (left) and the Sand Engine model (right). The Ameland Inlet is the easternmost inlet.

\section{AMELAND INLET}

\section{Default model - radar data comparison}

Following the above-described modeling approach, a model simulation was carried out for the hindcast period (27-28 January 2010), in which default model settings were applied as defined in the model calibration study (see Deltares, 2009). First, the water levels and wave propagation were validated on the Wadden Sea scale showing good overall model performance. Next, the local model results in the Ameland Inlet were compared to the Seadarq velocity fields, of which a total of 65 were available. To make a fair comparison between the model results and the radar data, the model results were first translated to the Seadarq output grid by spatially averaging over an area of $960 \times 960 \mathrm{~m}$, comparable to the processing of the radar images.

The resulting vector fields of the default computation were compared with the radar current vector fields, see e.g. Figures $8 \mathrm{a}$ and $9 \mathrm{a}$. The default model simulation shows a fairly good agreement with the radar current data, especially when taken into account that no model tuning has been applied yet and that a comparison is made between depth-averaged and surface currents. However, differences were found for a number of processes:

1. the flow divergence in the flood flow (Figure 8a). At the northwestern tip of Ameland, a flow divergence zone is situated, where the current splits either eastward along the coast or southward into the Wadden Sea. The radar data shows a stronger rotation over the ebb delta, whereas the model result shows a more northerly approach flow towards the inlet.

2. the eddy formation on the ebb flow (Figure 9a). Over the shallow area connected to Ameland, a distinct large-scale ( $\sim \mathrm{km}$ diameter) eddy can be observed in the radar data; this eddy is not as pronounced in the Delft3D results and does not persist as long as observed in the radar current fields.

3. the timing of flow reversal; an offset of approximately $30 \mathrm{~min}$. in timing of flow reversal between the radar and model data is evident.

Even though the radar observations contain uncertainties, the coherent spatial current structures in the radar data reappear in subsequent tidal cycles. Moreover, the presence of the eddy and the flow divergence is supported by visual inspection of radar imagery (a movie of time-averaged radar images showing surface flow patterns). This lends credence to - at least - the reliability of the radar current directions. Therefore, the observed model - data differences are considered an indication of modelling inaccuracies, since these differences are based on the spatial patterns of the radar current measurements rather than on the absolute value of the currents. 

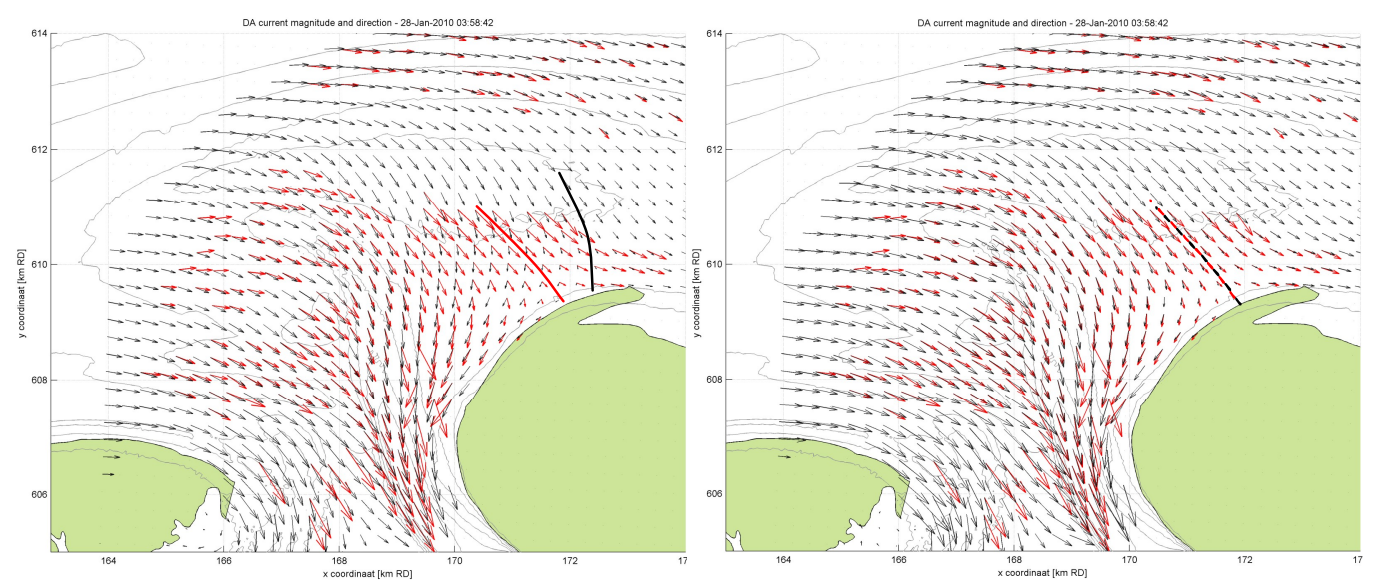

Figure 8: Measured (red) and modelled (black) current vector field for the reference run (left) and for the run based on the roughness predictor (right), at maximum flood flow. The solid lines indicate the flow divergence in the radar data (red) and model results (black).
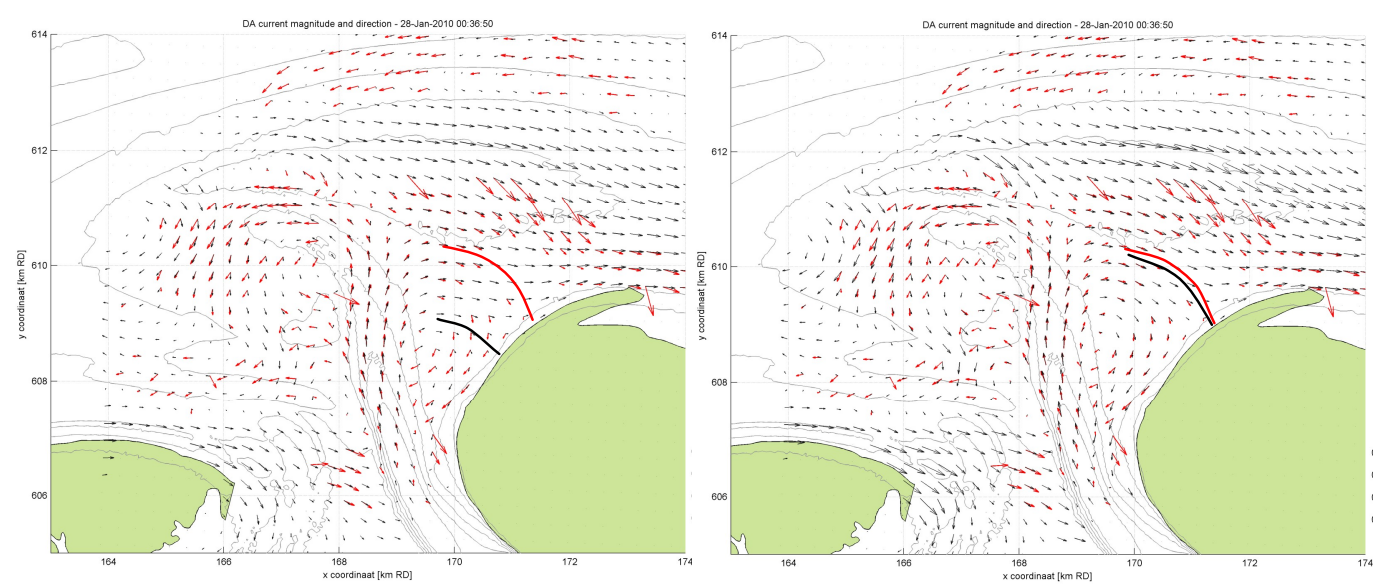

Figure 9: Measured (red) and modelled (black) current vector field for the default run (left) and for the run based on the roughness predictor (right), at low water slack. The solid lines indicate the flow divergence in the radar data (red) and model results (black).

\section{Optimization of model - radar data comparison}

A range of sensitivity simulations was performed in an attempt to optimize the correspondence between the model and radar data. The model results proved to be relatively insensitive to a range of model settings, which are discussed by Deltares (2010) and Swinkels and Bijlsma (2012). A significant improvement over the default model run was achieved by incorporating the Van Rijn roughness predictor. This recent Delft3D add-on computes the space- and time-varying bedform roughness heights accounting for ripples, mega ripples and dunes, based on the local sediment diameter $\left(D_{50}\right)$, flow conditions and wave conditions (see Van Rijn, 2007). With the roughness predictor switched on, it was found that especially in the shallow nearshore area, significantly lower bed roughness values were computed than initially applied in these regions based on default uniform Manning values.

Figure $8 \mathrm{~b}$ and $9 \mathrm{~b}$ show the improved flow patterns computed by the model including the roughness predictor. The lower bed roughness of the ebb delta shoal connected to Ameland leads to a different approach flow towards the inlet and the formation of a stronger and larger-scale eddy. This matches better with the observed current patterns from the radar data. Moreover, the computed moment of flow reversal shifts forward in time and now corresponds well with the radar data.

Error statistics derived for the entire radar data period for velocities and directions for the default and optimized model are presented in Table 1 and show a high correlation between the optimized 
model and radar data. Even though there are no in-situ measurements available to validate the radar data and the model results, the high agreement between the optimized model and the radar data provides initial confidence in the validity of the flow patterns derived from the radar images. Moreover, it suggests that the model results may be improved by applying a space- and time-varying bed roughness as proposed by Van Rijn (2007).

\begin{tabular}{|c|c|c|}
\hline & Default settings & Optimized settings \\
\hline \multicolumn{3}{|l|}{ Magnitudes } \\
\hline Bias & $-0.09 \mathrm{~m} / \mathrm{s}$ & $-0.03 \mathrm{~m} / \mathrm{s}$ \\
\hline RMSE & $0.23 \mathrm{~m} / \mathrm{s}$ & $0.19 \mathrm{~m} / \mathrm{s}$ \\
\hline Scatter Index & $36 \%$ & $32 \%$ \\
\hline Symmetric slope & 0.84 & 0.95 \\
\hline Corr.coefficient & 0.77 & 0.83 \\
\hline \multicolumn{3}{|l|}{ Directions } \\
\hline RMSE & $39^{\circ}$ & $30^{\circ}$ \\
\hline Scatter Index & $9.0 \%$ & $9.8 \%$ \\
\hline Corr.coefficient & 0.65 & 0.79 \\
\hline
\end{tabular}

\section{SAND ENGINE}

The radar system at the Sand Engine was installed only recently (June 2012) and up to today, the radar and software settings have not been fully tuned. Therefore, the discussion below is a preliminary analysis of the available data which is likely to be updated and extended in the near future.

\section{Default model results}

Following the modeling approach of the Ameland Inlet, a simulation was carried out for the hindcast period (8-10 June 2012) with similar default model settings. Again, the local model results were compared to the Seadarq velocity fields, of which a total of 175 were available. Generally, the flow patterns along this part of the Dutch coast are bi-directional with northeasterly flow on the rising tide and southwesterly flow on the falling tide. As the Sand Engine forms an obstruction to the tidal currents, the flow accelerates and an eddy with approximate diameter of $1 \mathrm{~km}$ forms in its lee on both tides. The flow acceleration is evident from both the model results and from the radar data. The eddy can be visually observed from aerial photographs, from radar snap shots (time-averaged images, see Figure 10a) and from the high-resolution model results. However, the radar current fields and processed model results do not show this circulatory flow, which is presumably caused by the Seadarq resolution that is too coarse to resolve the eddy.
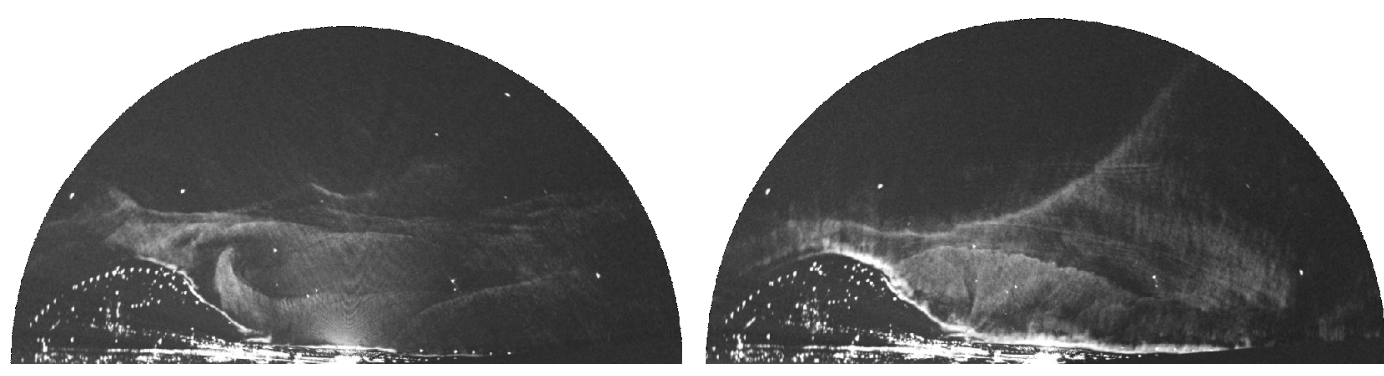

Figure 10: Radar snap shots (time-averaged radar image). Left: moment of maximum flood currents (from south to north; left to right in the image) when an eddy forms in the lee of the Sand Engine. Right: moment of rising tide when a clear density front passes the Sand Engine.

A first comparison between the 2DH model results and radar data shows a large underestimation of the modeled velocities compared to the radar current magnitudes and large differences in current directions at specific moments in the tidal cycle (see Figure 11a and b). From the radar data, offshore directed surface currents are evident from high water slack to about one to two hours afterwards. These currents are considered to be related to three-dimensional circulations driven by density differences. The Sand Engine is located $10 \mathrm{~km}$ north of the mouth of the River Rhine (see Figure 1), 
with an approximate average fresh water discharge of $1500 \mathrm{~m}^{3} / \mathrm{s}$. Each tidal cycle, a body of fresh to brackish water is advected to the North, which, under the right conditions, forms a sharp density front with the surrounding salt water. Such fronts can be visually observed in the field by a sharp color difference and are, due to the distinct difference in small scale surface roughness, also obvious from time-averaged radar images (see e.g. Figure 10). The stratification may lead to strong cross-shore exchange flows, which were also suggested to develop in this environment by De Boer (2009).

Obviously, a depth-averaged model approach is not adequate in a stratified environment and comparison of the depth-averaged model results to the radar observed surface currents is therefore not appropriate. To make a fair comparison, a three-dimensional model should be applied taking into account density-driven flows due to salinity and/or temperature. On the other hand, it is unknown what the radar currents represent in a stratified environment: the effective current encountered by the waves may be strongly determined by the stratified conditions (possibly with varying current directions and strengths over depth) and it is questionable whether the linear dispersion relation can be applied in this case.

As mentioned before, the radar current data have not been validated yet. A first set of ADCP measurements has recently been collected, now allowing for a comparison of the radar data to in-situ data and a further analysis of the density-driven currents around the Sand Engine. It is hypothesized that stratification only plays a role during certain phases in the spring-neap cycle and during certain tidal stages, which would imply a temporal variation in the validity of the radar current data. This is to be further investigated.
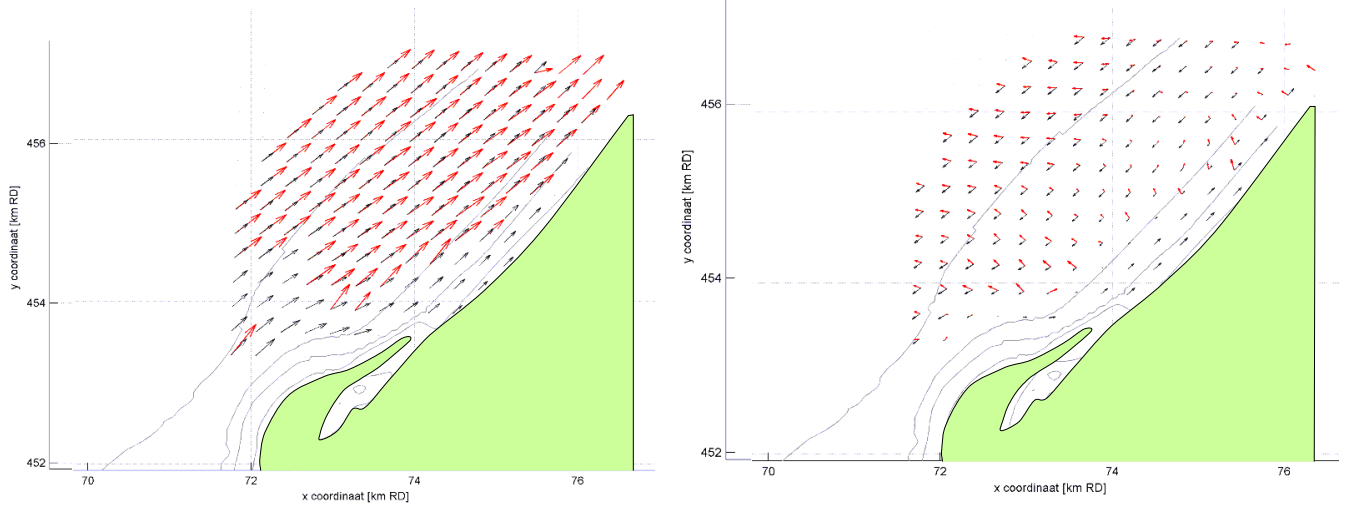

Figure 11: Measured (red) and modelled (black) current vector field for a moment of maximum flood flow (left) and a moment 1 hour after high water slack (right).

\section{CONCLUSIONS}

In this explorative study, we investigated current patterns from radar data and compared these with model results for two field sites. Even though the radar data have not been validated against insitu measurements yet and their quality is unknown, the data have provided valuable insight in the two coastal systems. From the radar data, coherent large-scale spatial flow patterns were detected, such as eddies, flow divergence zones and density-driven surface currents. The occurrence of these flow features is supported by visual observations from radar snap shots, which lends credence to - at least - the radar derived current directions. The high agreement between the optimized model of Ameland and the radar current data further provides confidence in the validity of the flow patterns derived from the radar images.

The radar current data is found to be very promising in non-stratified, shallow coastal regions, even in an area with complex bathymetry and flow patterns. The applicability of radar current data in deeper environments with temporal stratification is still uncertain and has to be further investigated.

Overall, it is concluded that the information on spatial current structures derived from radar images is exceptional and potentially of large value to coastal engineers. Considering the unique spatial and temporal data coverage compared to conventional in-situ measurements, the radar current data may serve as a valuable data source for coastal studies. It is now necessary to gain more insight in the quality of the radar data by ground-truthing against in-situ data in order to fully benefit from the radar data. 


\section{ACKNOWLEDGMENTS}

The study was partly funded by the SBW research program (Strength and Loads of Water Defenses), commissioned by Rijkswaterstaat, Ministry of Infrastructure and Environment. Nortek is kindly acknowledged for providing the Seadarq radar data.

\section{REFERENCES}

Alkyon. 2006. The integration of remote sensing and numerical wave and current modeling in an area with complex bathymetry. Alkyon report A1101R1. Author: G.Ph. van Vledder.

De Boer, G. J. 2009. On the interaction between tides and stratification in the Rhine Region of Freshwater Influence. Ph.D. Thesis, Technical University of Delft

Deltares. 2009. SBW Wadden Sea, water level modeling: Calibration hydrodynamic model. Deltares Report 120114-005, phase 2. Author: R. de Graaff

Deltares. 2011. Storm hindcast January 2010 - Analysis of the application of radar current data for hindcast purposes. Deltares report 1202119-001. Author: C.M. Swinkels.

Gautier, C., Peters, H. and Heesen, 2012a. J. Hydrodynamic data from radar observations. Proceedings of Hydrol2, in preparation.

Gautier, C. and Groeneweg, J. 2012b. The use of spatial radar observations in wave hindcasts. Proceedings of $33^{\text {rd }}$ International Conference on Coastal Engineering, 2012.

Gerritsen, H., De Vries, H. and Philippart, M. 1995. The Dutch Continental Shelf model. Coastal and Estuarine Studies. Volume 47. American Geophysical Union, Washington, DC.

Kuijper, E.V.L. 1993. Het 3D-KUSTSTROOK-model gebaseerd op TRIWAQ-in-SIMONA. WL | Delft Hydraulics report.

Van Rijn, L.C. 2007. Unified view of sediment transport by currents and waves. 1: Initiation of motion, bed roughness and bed-load transport. Journal of Hydraulic Engineering, 133(6), 668689.

Swinkels, C.M., Bijlsma, A.C. 2012. Understanding the hydrodynamics of a North Sea tidal inlet by numerical simulation and radar current measurements. Proceedings of $3^{\text {rd }}$ International Symposium on Shallow Flows, Iowa City, USA, June 4 - 6, 2012. 